\title{
Carbon coated porous titanium niobium oxides as anode materials of lithium ion batteries for extreme fast charge applications
}

Hailong Lyu ${ }^{\mathrm{ab} *}$, Jianlin Lic ${ }^{\mathrm{c}}$, Tao Wang ${ }^{\mathrm{b}}$, Bishnu P Thapaliya ${ }^{\mathrm{ab}}$, Shuang Men ${ }^{\mathrm{a}}$, Charl J. Jafta ${ }^{\mathrm{ac}}$, Runming Tao ${ }^{\mathrm{b}}$, Xiao-Guang Sun ${ }^{\mathrm{a}^{*}}$, and Sheng Dai ${ }^{\mathrm{ab}^{*}}$

${ }^{a}$ Chemical Sciences Division, Oak Ridge National Laboratory, Oak Ridge, TN 37831, USA.

${ }^{\mathrm{b}}$ Department of Chemistry, University of Tennessee, Knoxville, TN 37996, USA

${ }^{\mathrm{c}}$ Energy and Transportation Science Division, Oak Ridge National Laboratory, Oak Ridge, TN 37830, USA

*Corresponding authors. E-mail: 1yuh@ornl.gov; sunx@ornl.gov; dais@ornl.gov 

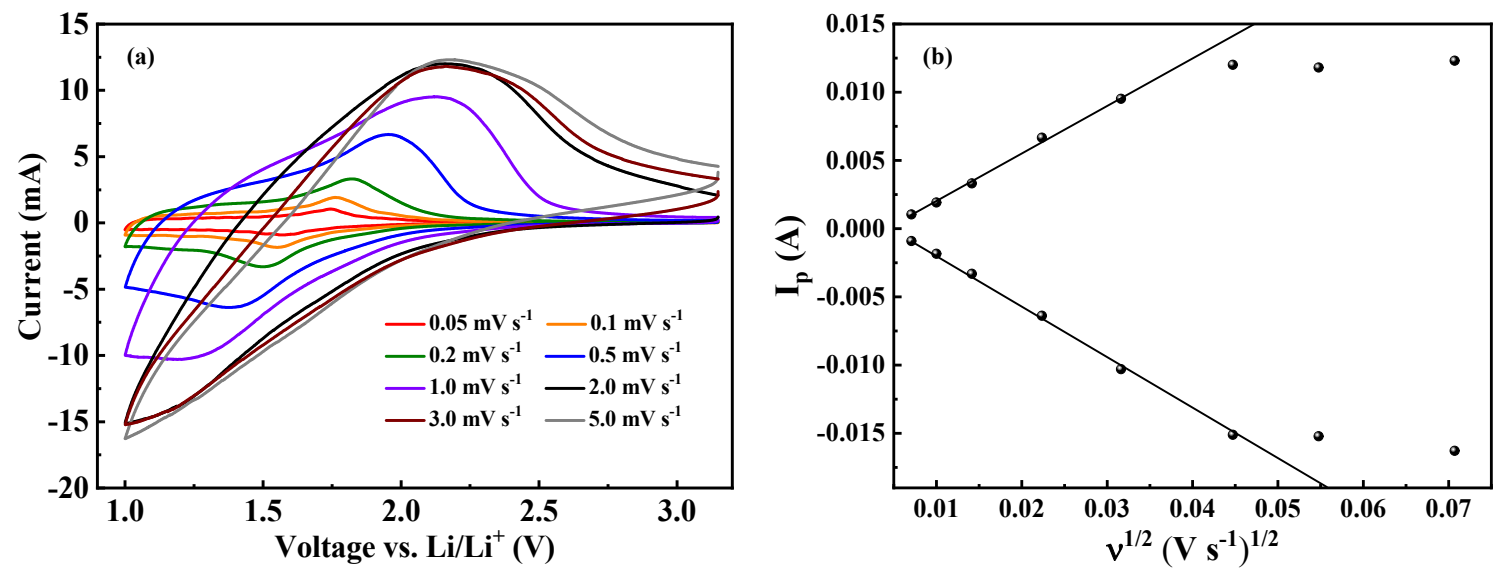

Figure S1. (a) CV profiles of TNO@C half-cell at various scan rates from 0.05 to $5.0 \mathrm{mV} \mathrm{s}^{-1}$; (b) relationships between the peak current $\left(\mathrm{I}_{\mathrm{p}}\right)$ and the square root of scan rate $\left(v^{1 / 2}\right)$ in lithiation and delithiation processes of TNO@C half-cell.

The Li ion diffusion coefficients are calculated using the Randles-Sevcik equation (Eqn. 1):

$$
I_{p}=269000 n^{3 / 2} A D^{1 / 2} C v^{1 / 2}
$$

In Eqn. $1, I_{p}$ is the peak current $(\mathrm{A}), n$ is the electrons concentration per molecule during the redox reactions, $A$ is the surface area of the electrodes $\left(\mathrm{cm}^{2}\right), D$ is the diffusion coefficient of lithium ions $\left(\mathrm{cm}^{2} \mathrm{~s}^{-1}\right), C$ is the bulk concentration of lithium ions in electrodes $(\mathrm{mol} \mathrm{cm}-3)$ and $v$ is the scan rate $\left(\mathrm{V} \mathrm{s}^{-1}\right)$. A linear relationship between $I_{p}$ and $v^{1 / 2}$ can be found according to Eqn. 1, as well as the results displayed in Figure S1b. The diffusion coefficients of lithium ions in TNO@C are calculated through the slopes, which are estimated to be $2.39 \times 10^{-12}$ and $2.13 \times 10^{-12} \mathrm{~cm}^{2} \mathrm{~s}^{-1}$ for lithiation and delithiation processes, respectively. Besides, the values of $I_{p}$ change little above the scan rate of $2.0 \mathrm{mV} \mathrm{s}^{-1}$, that is, about 16.67 mins scan time, suggesting the diffusion coefficient of lithium ions would be the limitation to extreme fast charging (XFC) performance of high-loading TNO@C anodes shorter than 16.67 mins. 

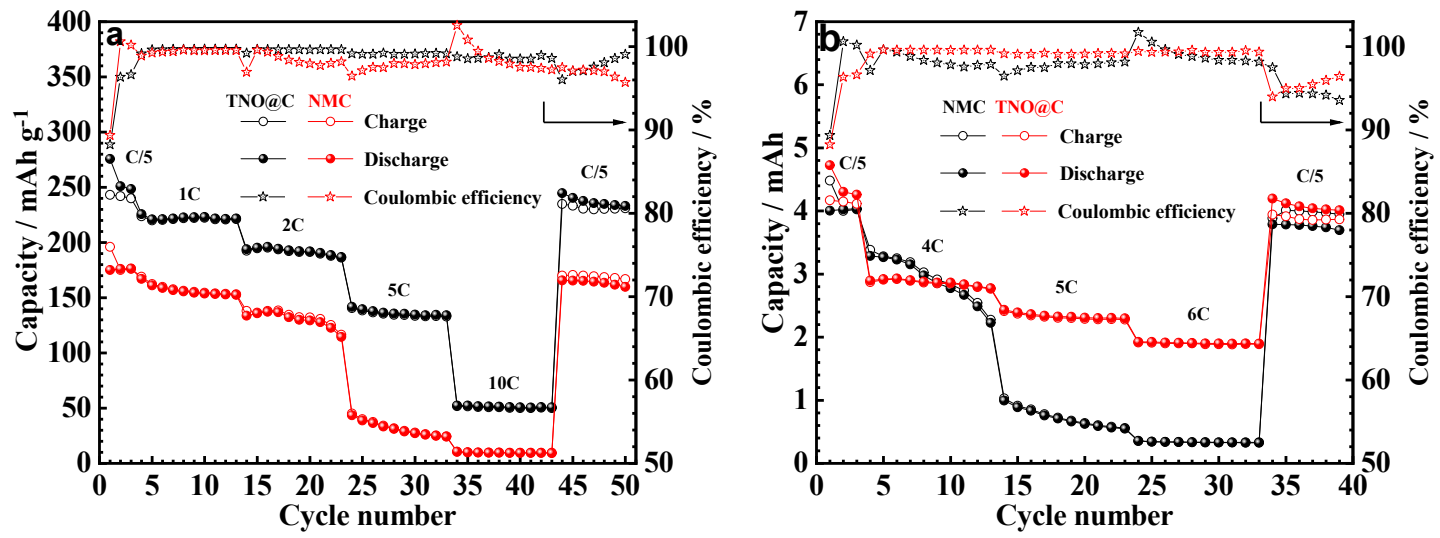

Figure S2. (a) Specific capacities and coulombic efficiencies and (b) high rate performance and coulombic efficiencies of NMC and TNO@C half-cells (18 and $13.5 \mathrm{mg} / \mathrm{cm}^{2}$ for NMC622 and TNO@C, respectively).

For the NMC half-cell, the charge rates changed while the discharge rate was fixed at $\mathrm{C} / 3$, whereas for the TNO@C half-cell, the discharge current rates changed while the charge rate was fixed at C/3 (1C=150 mA/g for NMC622 and $200 \mathrm{~mA} / \mathrm{g}$ for TNO@C).

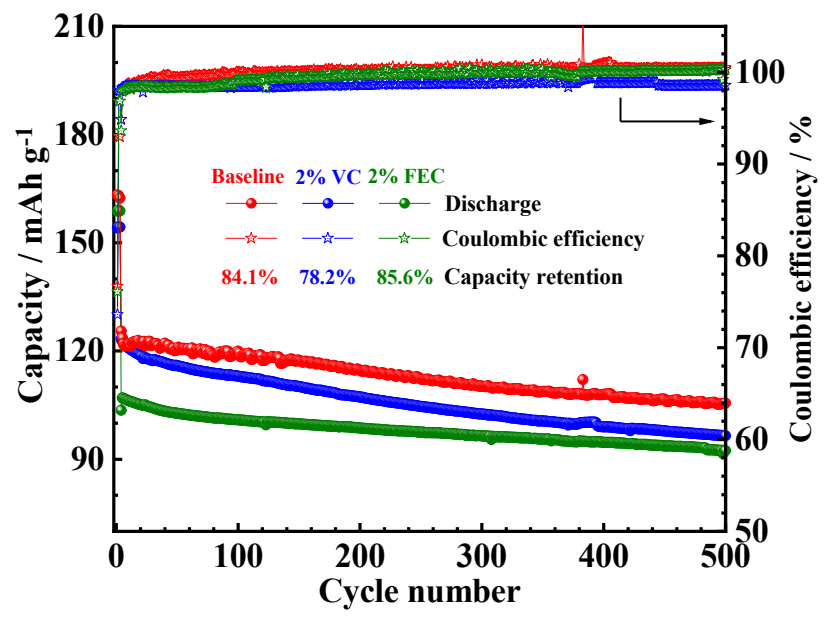

Figure S3. Cycling performance of NMC/TNO@C full-cells with different electrolytes under the $5 \mathrm{C}$ charging protocol. 


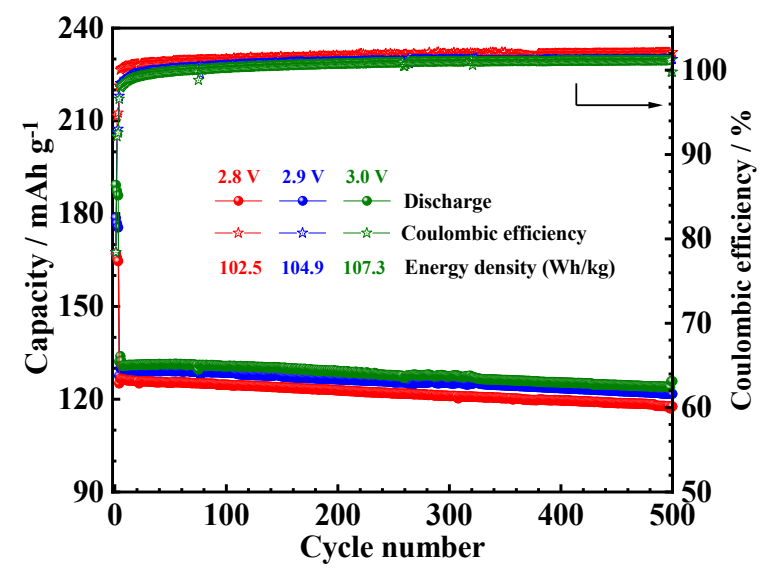

Figure S4. Cycling performance of NMC/TNO@C full-cells with different upper cut-off voltages under the $4 \mathrm{C}$ charging protocol.

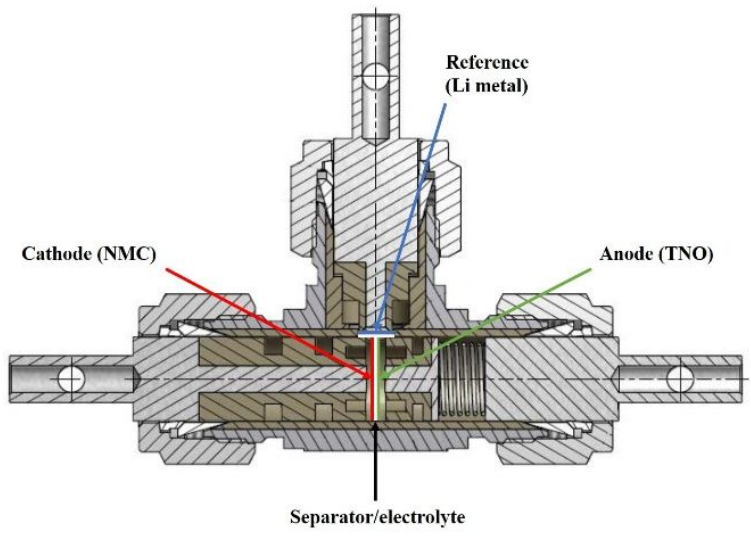

Figure S5. Schematic illustration of the three-electrode Swagelok full-cell. 

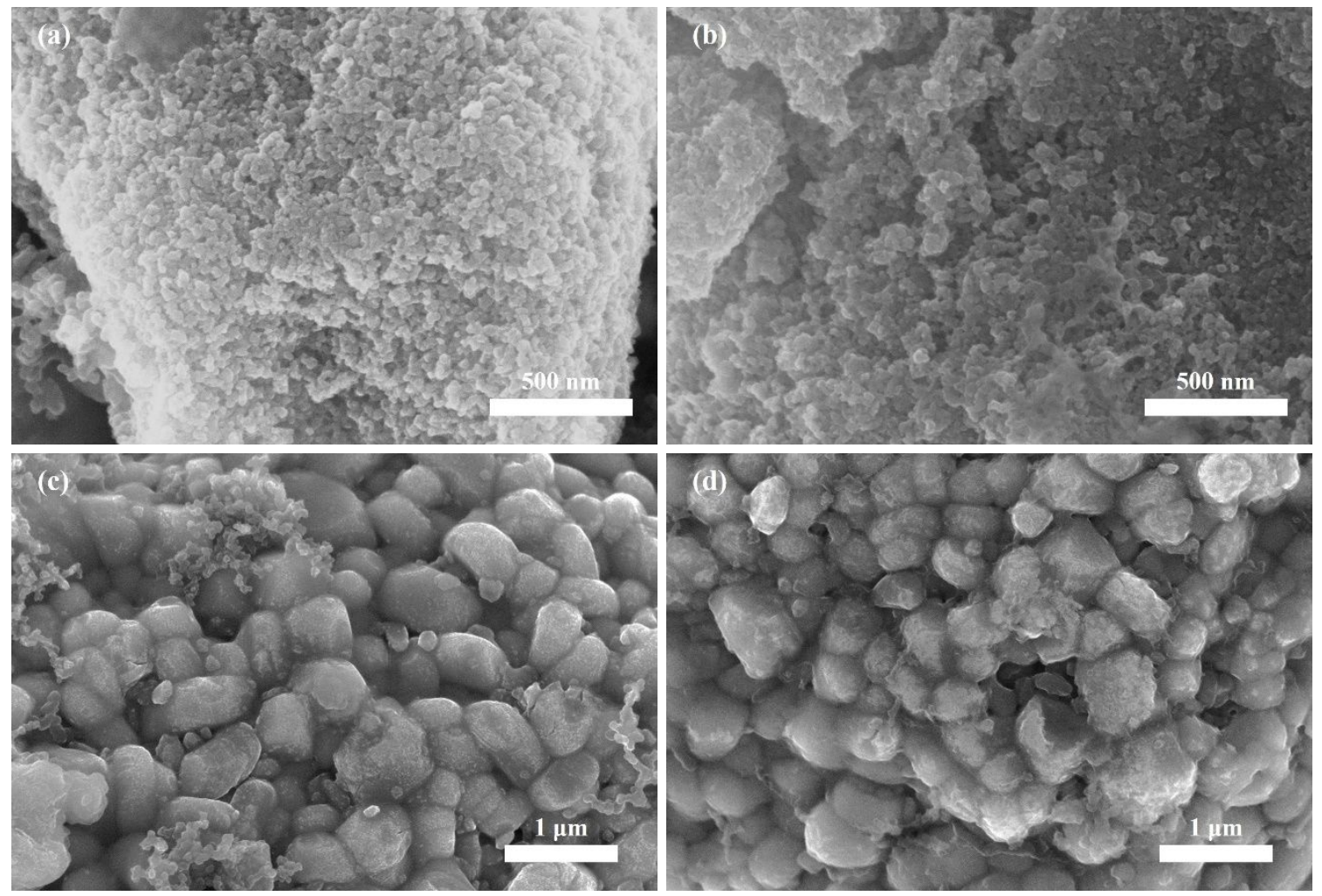

Figure S6. SEM images of (a \& b) TNO@C and (c \& d) NMC electrodes (a \& c) before and (b $\&$ d) after XFC cycling, respectively.

Table S1. Energy density and energy retention of NMC/TNO@C full-cells with different TNO loadings.

\begin{tabular}{|c|c|c|c|c|}
\hline TNO loading $\left(\mathrm{mg} / \mathrm{cm}^{2}\right)$ & 4.3 & 6.8 & 9.5 & 13.4 \\
\hline Mass energy density $(\mathrm{Wh} / \mathrm{kg})$ & 105.6 & 106.7 & 114.7 & 102.5 \\
\hline Volume energy density $(\mathrm{Wh} / \mathrm{L})$ & 264 & 267 & 287 & 256 \\
\hline Energy retention after 500 cycles $(\%)$ & 96.5 & 92.7 & 85.6 & 88.5 \\
\hline
\end{tabular}


Table S2. Electrode voltages of the three-electrode full-cell at different current rates with a voltage range of $1.5-3.2 \mathrm{~V}$.

\begin{tabular}{|c|c|c|c|c|c|c|}
\hline & \multicolumn{3}{|c|}{ NMC cathode } & \multicolumn{3}{c|}{ TNO@C anode } \\
\hline Voltage (V) & $\begin{array}{c}\text { Discharging } \\
\text { limit }\end{array}$ & $\begin{array}{c}\text { Charging } \\
\text { limit }\end{array}$ & Window & $\begin{array}{c}\text { Charging } \\
\text { limit }\end{array}$ & $\begin{array}{c}\text { Discharging } \\
\text { limit }\end{array}$ & Window \\
\hline C/10 & 3.46 & 4.15 & 0.69 & 1.95 & 0.95 & 1.00 \\
\hline $4 \mathrm{C}$ & 3.37 & 4.31 & 0.94 & 1.90 & 1.12 & 0.78 \\
\hline 5C & 3.36 & 4.33 & 0.97 & 1.86 & 1.14 & 0.72 \\
\hline $6 \mathrm{C}$ & 3.35 & 4.34 & 0.99 & 1.85 & 1.16 & 0.69 \\
\hline
\end{tabular}

Table S3. Concentrations of XPS characteristic peaks for NMC and TNO@C electrodes before and after XFC cycling.

\begin{tabular}{|c|c|c|c|c|}
\hline Characteristic peaks & Fresh NMC & Cycled NMC & Fresh TNO@C & Cycled TNO@C \\
\hline C-C, $\mathrm{C}-\mathrm{H}$ & $40.72 \%$ & $35.22 \%$ & $47.59 \%$ & $31.93 \%$ \\
\hline $\mathrm{C}-\mathrm{OH}, \mathrm{C}-\mathrm{O}-\mathrm{C}$ & $18.60 \%$ & $26.41 \%$ & $17.97 \%$ & $19.53 \%$ \\
\hline $\mathrm{C}=\mathrm{O}$ & $15.89 \%$ & $14.82 \%$ & $12.49 \%$ & $23.60 \%$ \\
\hline $\mathrm{O}-\mathrm{C}=\mathrm{O}$ & $4.02 \%$ & $9.69 \%$ & $5.69 \%$ & $9.33 \%$ \\
\hline $\mathrm{PVDF}$ & $20.78 \%$ & $13.86 \%$ & $16.25 \%$ & $15.60 \%$ \\
\hline $\mathrm{C}=\mathrm{O}$ & $56.18 \%$ & $65.53 \%$ & $31.79 \%$ & $48.16 \%$ \\
\hline $\mathrm{O}-\mathrm{C}=\mathrm{O}$ & $14.47 \%$ & $34.47 \%$ & $9.88 \%$ & $22.54 \%$ \\
\hline $\mathrm{O}^{2-}$ & $29.35 \%$ & N/A & N/A & N/A \\
\hline $\mathrm{O}-\mathrm{H}$ & $\mathrm{N} / \mathrm{A}$ & $\mathrm{N} / \mathrm{A}$ & $58.33 \%$ & $29.31 \%$ \\
\hline $\mathrm{C}-\mathrm{F}$ & $100 \%$ & $78.40 \%$ & $100 \%$ & $79.89 \%$ \\
\hline $\mathrm{LiF}$ & N/A & $21.60 \%$ & N/A & $20.11 \%$ \\
\hline
\end{tabular}

